\title{
Stem cell legislation and its impact on the geographic preferences of stem cell researchers
}

\author{
Luca Verginer $^{1,2}$ (D) Massimo Riccaboni ${ }^{2,3}$ (D)
}

Received: 6 March 2020 / Revised: 30 November 2020 / Accepted: 8 January 2021 /

Published online: 15 February 2021

(c) The Author(s) 2021

\begin{abstract}
Proponents describe stem Cell Replacement Therapy and related technologies to be a significant step forward for medicine. However, due to the inherent ethical problems in human Embryonic Stem Cell Research (hESC), it is strictly regulated around the world. The US has passed at the federal and state level, both supportive and restrictive laws over the years. The changing legislative environment at the state and federal levels has created a situation whereby researchers have to choose whether and where to carry out this research. By exploiting the temporal and spatial heterogeneity and legislative shocks, we assess if the affected scientists have voted with their feet, leaving the state or country imposing restrictive rules and whether hESC research has clustered geographically. We find that most of the hESC research is carried out in supportive states, and significant legislative changes have had a minor but noticeable effect on relocation choices. Most importantly, the research has moved to supportive states. This result suggests that several state-level interventions (supportive), which were opposed to federal laws (restrictive), have counteracted each other.
\end{abstract}

Keywords Stem cell research · Geographic labor mobility · Policy impact analysis

\section{Introduction}

There is little doubt about the potential for stem cell-derived therapies to tackle many hitherto incurable diseases (e.g., neurodegenerative disorders such as Parkinson or Alzheimer). However, significant fundamental research on Stem Cells (SC) in general and human embryonic stem cells (hESC), in particular, is required

Luca Verginer

lverginer@ethz.ch

1 Chair of Systems Design D-MTEC, ETH Zurich, Weinbergstrasse 56/58, 8092 Zürich, Switzerland

2 IMT School for Advanced Studies Lucca, Piazza S. Francesco, 19, 55100 Lucca, Italy

3 MSI-KU Leuven, Naamsestraat 69, 3000 Leuven, Belgium 
before such treatments can be offered to the public. Beyond the significant initial investment in basic research, there are major ethical concerns with regards to human embryonic stem cell (hESC). As part of the preparation and extraction of such a cell culture, a human embryo is destroyed. For this reason, human embryonic stem cell research is a controversial field of research, which has led various countries to either heavily regulate or ban it outright. Nevertheless, the therapeutic potential and the commercial value of stem cell-derived treatments have created incentives to continue this research.

In the US from the early Nineties, various laws have been passed at federal, and several more at the state level, affecting funding and the legality of stem cell research. Some states have adopted a more supportive stance by supplanting federal funding restrictions. Several other US states, on the other hand, passed legislation which practically ended research into the technology before it started. In this work, we look at how the changing legislation has affected the location choice of Stem Cell researchers. Specifically, we look at the interplay of federal and state legislation to assess how they affected hESC research relocation choices as well as their geographical distribution. We assess first, to what extent, a state's stance on the hESC issue has influenced the presence of hESC scientists. Secondly, we look at two significant and sudden legislative interventions, i.e., the Bush Funding Ban (federal level) and Proposition 71 in California (state level).

To address this question, we compile a comprehensive dataset of disambiguated authors, their affiliations and the text of their publications. With this extensive dataset on individual level scientist mobility, we estimate the impact of several policies on the relocation choice of US hESC researchers over a decade (1998-2008). This period covers the early beginnings of the field up to the Bush administration, which saw a federal moratorium on funding. More importantly, the period between 2001 and 2006 is a crucial time when US Stem Cell laws were forged and influence the research landscape to this day (Acosta and Golub 2016; Alberta et al. 2015). Restrictive legislation has arguably a chilling effect on research activity. This overall reduction of research is the result of the combined effect of (1) researchers staying with their institution but reducing their work on the subject and (2) move to more permissive locations. We are interested in the second mechanism. Within US borders, as already argued, laws have been enacted to regulate this nascent field, and the extant literature suggests that restrictive interventions have stymied research (Owen-Smith and McCormick 2006), caused hESC researchers to move abroad and supportive interventions to increase scientific output (Alberta et al. 2015). The state and federal legislative changes are a source of shocks we can exploit to identify if researchers voted with their feet. Besides, the US has a substantial resident scientist population, which allows us to identify several likely affected scientists as well as comparing their choices against the US life scientists working in other fields of research. Levine (2012) argues that hESC researchers express a preference to relocate to the US states perceived to be less restrictive. The study, based on surveys, suggests that expressed preferences are an indication that the participants would act upon it. More specifically, the authors find that a state's stance on hESC correlates with their ranking in their survey. 


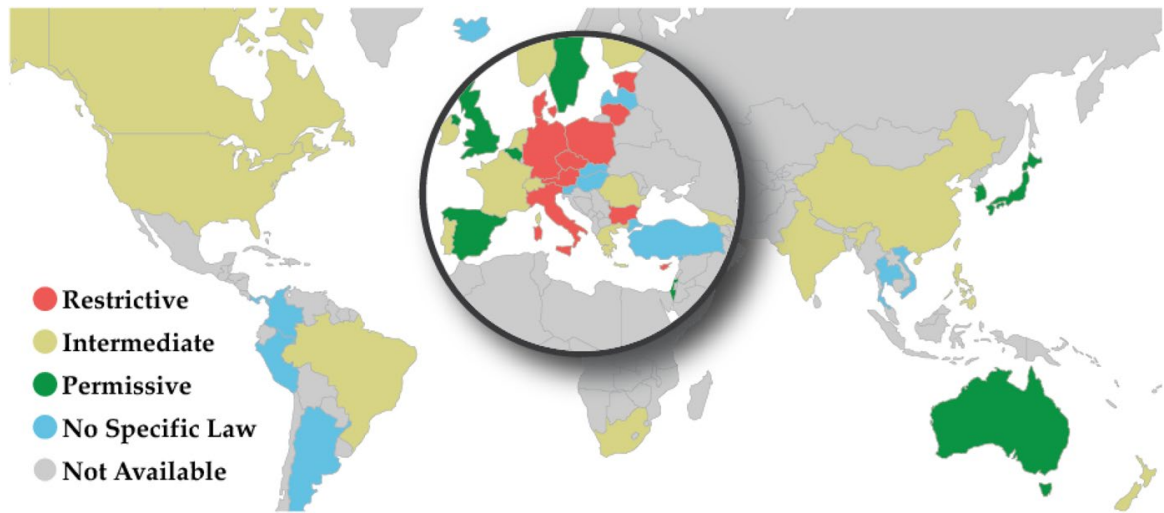

Fig. 1 The state of global hESC Research policies as of 2014. The map is based on the information compiled by StemGen (2017), Russo (2005) and Levine (2008)

The legislative events at federal and state level offer a unique opportunity to evaluate how the diverging interests at the two levels counteract or amplify each other. The differential impact of federal and state hESC legislation is a textbook example the "States as Laboratories of Democracy". This idea can be traced back to US Supreme Court Justice Brandeis in 1932. Brandeis declared that: "It is one of the happy incidents of the federal system that a single courageous State may, if its citizens choose, serve as a laboratory; and try novel social and economic experiments without risk to the rest of the country". Therefore our analysis, beyond the specific issue of hESC research laws, can also be viewed as a case study of how state laws have been used to counterbalance federal regulation.

\section{Historical overview of stem cell research and regulation}

In 1981, scientists were first able to derive embryonic stem cells from mice embryos (Department of Health and Human Services 2015) marking the early beginning of stem cell research. The cloning of mammalian cells by Wilmut et al. (1997) and the derivation of the first hESC lines by Thomson (1998) highlighted the possibilities and ethical implications of the technology. The source of the ethical conundrum lies in the process by which hESC lines are derived, which involves the destruction of human embryos. States and the federal government have since stepped into regulating the field (Levine et al. 2013).

Stem Cells are cells, which have not yet specialized to become more specialized types of cells (e.g. a muscle, red blood or brain cell) but are still able to do so and can renew and divide themselves (Department of Health and Human Services 2015). We distinguish two types of stem cells embryonic and adult. Both can become more specialized. However, embryonic cells are thought to be more "versatile" and are far easier to be cultured. In contrast, adult stem cells are more difficult to obtain in large numbers, something that is necessary for replacement therapies (Department 
of Health and Human Services 2015). Takahashi and Yamanaka (2006) discovered a method to "reprogram" specialized adult cells to regain certain hESC like features. These induced pluripotent stem cells (IPSCs) are an important new avenue for research, which reduces the need for hESC cells in several cases. However, for the period under investigation, i.e., 1998 to 2008, hESC was the most prevalent form of Stem Cell research, while IPSC has influenced Stem Cell research trajectories since then (Scott et al. 2011).

Globally, hESC research laws are very disparate. Some commentators (Caulfield et al. 2009; Russo 2005) describe it as a "patchwork of patchworks", mimicking at a global level, what we observe in the US. This patchwork is illustrated by the Stem Cell World Map (see Fig. 1), compiled by StemGen (2017) and the similar classification by Russo (2005). On the map, we note the varied approaches governing EU countries, with Italy and Germany adopting a restrictive approach and the UK and Belgium being more permissive in the kinds of experiments tolerated and the variety of Cell Lines made available for research. At a global scale similar to the US, we have very different approaches to this emotionally and ethically charged field of research.

The first federal response to the potential future development of hESC was the Dickey-Fuller Amendment in 1996. The amendment bans any federal funding for “ (1) the creation of a human embryo or embryos for research purposes; or (2) research in which a human embryo or embryos are destroyed, discarded ..." (Kearl 2010). This amendment has been attached to every appropriations bill for the Departments of Health and Human Services, Labor, and Education since 1996. This amendment makes federal funding unavailable, but does not outright ban hESC research as such, as evidenced by Thomson's (1998) Breakthrough in 1998 (see Fig. 2).

Several states responded to the federal vacuum by passing legislation at the state level. These laws address in part the legality of research on embryos, the consent requirement to research on fetus/embryos or restrictions to purchase and sell human tissue. ${ }^{1}$ US states, after the Dickey-Fuller amendment, adopted legislation, which has been classified by Levine et al. (2013) as either restrictive or supportive. For example, in 1998, Rhode Island was the first state to propose relevant state legislation in favor of hESC and the same year, Michigan adopted legislation hindering hESC research. However, some states (e.g. Pennsylvania) had laws on their books even before the advent of the technology in 1998, on the subject of abortion, which indirectly affect the practicality of hESC research (National Conference of State Legislatures 2016). Which states are supportive or restrictive is shown in the timeline in Fig. 2 and shown on the map in Fig. 3, as they were in 2008.

The lines between supportive and restrictive states are blurry as the nuances of civil and criminal liabilities considered by the National Conference of State Legislatures (2016) shows. Moreover, even if National Conference of State Legislatures (2016) and Levine et al. (2013) have classified a state as either supportive or restrictive, state-level amendments and legislative proposals have been passed and

\footnotetext{
1 The National Conference of State Legislatures (2016) has an extensive breakdown of the various legal aspects considered by multiple states.
} 


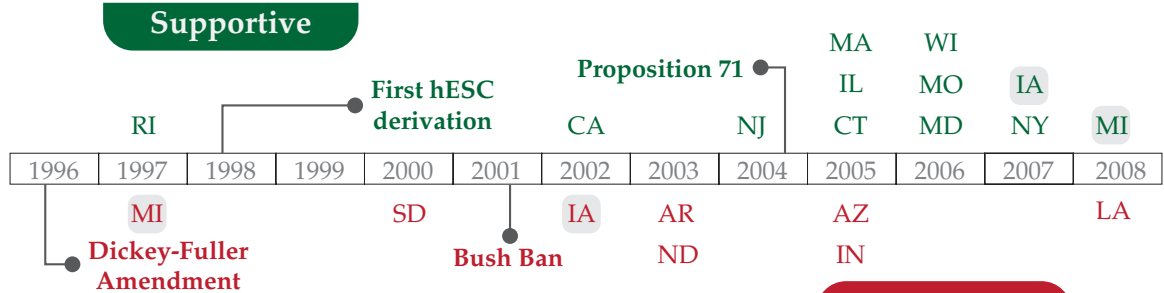

\section{Restrictive}

Fig. 2 Time-line of main Stem Cell legislation events in the USA. The events above the timeline can be broadly classified as "supportive", the events below "restrictive". The states (abbreviations) listed above and below, indicate the year in which a given state has adopted a supportive or restrictive stance. Note that IA and MI change from restrictive to supportive

Fig. 3 The map of the US highlights the stance of the individual states on hESC. Note: Territories which are not shown (e.g. Alaska) are all Baseline

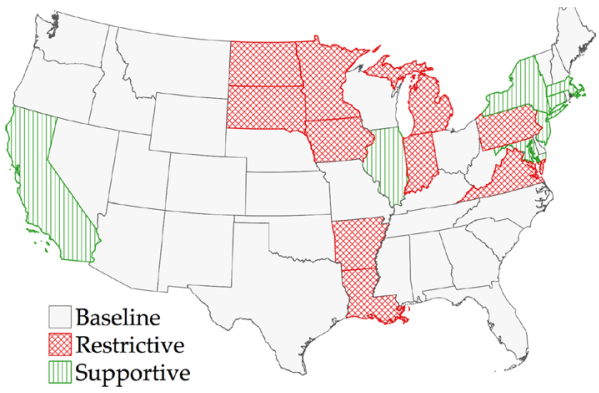

discussed without passing legislation. This ongoing debate in state capitols suggests that adopted legislation regarding funding and legal research practices is not a sudden shock to the resident scientist population. Instead, it is the culmination of legislative proposals and public opinion, which is also supported by the results of Levine et al. (2013). The long lead time to the passage of actual legislation means that the stance of a state would have been known to the relevant population well in advance. This observation implies two things for the analysis, (1) changing from supportive to restrictive or vice versa is not a shock and (2) the level of support, while not enacted by a specific law, characterizes the state further into the past. In other words, a state without specific hESC legislation which becomes supportive in a given year by passing legislation has already signaled either through proposed legislation or tolerant administration the stance of the state on the issue.

Beyond these state-level regulations, mostly affecting the practicality of hESC, there have been two fundamental state and federal laws concerning the critical aspect of research funding. Bush Banned in the August of 2001 any federal funding for hESC, exempting research into cell lines derived before the announcement. The ban does not only affect future funding, but any research on hESC done in the future may not be conducted on federally funded premises or equipment (Adelson and Weinberg 2010). As a countermove, California adopted the ballot initiative "Proposition 71" devoting 3 Billion Dollars to hESC. 
The funding made available by Proposition 71 in November of 2004 is to date the most generous state hESC funding scheme in the US. After California, several other states have adopted similar funding schemes (e.g. New Jersey, Massachusetts), although nowhere near the size of the 3 Billion provided by Proposition 71 (Acosta and Golub 2016). Both the generous funding and the signal to other states to start their funding schemes are arguably a significant legislative shock. We argue, therefore, that this event has affected increased mobility to California in particular and prevented moves abroad in general.

Immediately after the approval of Proposition 71 litigation regarding its legality prevented the disbursement of funds for research until 2006. As Acosta and Golub (2016) argue, during this period, the state built the administrative apparatus to evaluate and monitor future investments. This delay has then arguably had two effects on the hESC population. On the one hand, it made the financing less sure. Therefore, some researchers may have decided to move regardless. On the other hand, the ongoing work on the administrative framework was a signal to hESC scientists that California was serious about this initiative.

\section{Research hypotheses}

Scientific funding is one of the primary tools used to guide national research agendas, e.g., fundamental research into promising future industries, fields perceived to be of strategic importance among others. Public funding is critical in the development of fundamental research, for which a commercially viable application is a long way off. McMillan et al. (2000) find that public research, performed and funded primarily by the governments and academia is the main factor creating the groundwork for successful biotech products. In line with this finding, funding and research into the basic science of Stem Cell are in large part driven by public funding and not commercial ventures. Public funding was and still is a crucial driver in Stem Cell Research as illustrated by the billions of dollars of funding provided by California in 2006. We find that in the period under consideration and our dataset, only $2.7 \%$ of hESC researchers are affiliated with commercial entities (see Table 1).

Given the prevalence of stem cell research in academia, it stands to reason that the forces influencing the choice of research direction and mobility are influenced by the way academic careers are shaped. Following the reasoning of Vakili and Blomfield (2016), scientists need to balance access to funding while pursuing cutting edge research to garner academic prestige and recognition among their peers. For example, researchers interested in furthering their career in the field of stem cells and related therapeutic methods would be interested in hESC a field which according to Vogel (1999) and Holden (2004) was at the time one of the most promising areas of research. HESC researchers are constraint by funding and legal challenges; nevertheless, a breakthrough result in hESC has the potential to boost academic prestige and thus career prospects significantly. These two forces, academic recognition and funding opportunities counteract each other in the case of Stem Cell researchers. We argue that in a restrictive location, R\&D funding, support and potential for significant breakthroughs are reduced. This 
situation either leads scientists to (1) choose a different field where breakthrough results are more likely or to (3) relocate to more permissive states or countries. As argued above in this nascent field, private investment is negligible since commercial applications are far off, and a significant part of the work is basic science. Moreover, as found in Chessa et al. (2013), Morescalchi et al. (2015) and Verginer and Riccaboni (2020, 2021), the leadership of global science cities and countries is driven in large part by inter-city and international mobility. For these reasons, we look in this work specifically at the relocation and mobility.

Academic mobility is also influenced by many factors, beyond funding considerations. However, it would be hard to argue that funding and legal security to carry out one's research are not fundamental, especially given this field's lack of commercial applications in this period. Miguélez and Moreno (2014) analyzing mobility of inventors across European regions identifying job opportunities, the presence of social networks as drivers. There is also a stream of literature suggesting that amenities, e.g., mild weather, high-quality local infrastructure, quality of life, play a crucial role in determining the mobility of high skill labor (Glaeser et al. 2001; Florida 2002; Rappaport 2007). However, there has been mounting evidence that job availability is, unsurprisingly, a much more critical factor (Partridge 2010; Faggian et al. 2012; Cheshire and Magrini 2006). Overall the picture that emerges concerning drivers of mobility is that there are many factors, but that job availability is central and a "sine qua non". For this reason, we argue that the assumption that change in funding and legal status of a specific field of research directly affects the availability of jobs is a warranted since it represents a direct motivation for relocation and hence the main focus of our analysis.

Where scientists choose to relocate is a multi-faceted issue starting well before observed individual mobility. A first factor, which affects the observed mobility is the geographic distribution, i.e., where are these researchers located in general. If there are hardly any hESC researchers working in more restrictive states, and most researchers are already working in supportive states, this would imply that the population which could move is already biased. Therefore, before discussing mobility patterns and the impact of major legislative shocks, we will describe the distribution of scientists.

With this in mind, we propose the first hypothesis with regards to the mobility of researchers across states.

Hypothesis 1 (H1) hESC Researchers are more likely to move if they are located in restrictive states and chose preferentially supportive destinations.

We have noted that state and federal legislation is continuously evolving. Among these, there have been two significant events which could have reasonably affected the attractiveness of the US in general and California in particular. These two events are, (1) the heavy restrictions on federal funding for hESC research imposed by Bush in August 2001, henceforth the "Bush Ban" and (2) Proposition 71 in California. 
The Bush Ban prevents federal funds from being used for hESC research on non-approved stem cell lines and the derivation of any new cell lines (see the introduction for more details). Proposition 71, a Californian funding initiative passed in November of 2004, "authorizes a total of nearly \$3 billion in tax-free, general obligation state bonds to support stem cell research at California hospitals, medical schools, universities and other research institutions over ten years" (Baker et al. 2004, p. 2).

With regards to these two legislative changes, we formulate the following three hypotheses.

Hypothesis 2 (H2) hESC Researchers moved with a higher probability abroad, i.e., left the US, following the Bush Ban.

Hypothesis 3 (H3) hESC Researchers move in response to the approval of Proposition 71 with a higher probability to California.

Hypothesis 4 (H4) hESC researchers residing in California are less likely to leave the state following Proposition 71.

To assess if there has been any change in mobility patterns following these interventions, we will estimate the probability to move, not only overall as done for the interstate mobility but each year. If there is indeed a strong signal that mobility abroad or to/from California for hESC researchers changes after the two interventions they would show up as significant increases in mobility intensities above and beyond the general trend observed in the less exposed control groups.

\section{Data}

\subsection{Mobility}

We trace the mobility of researchers by looking at the affiliations listed on their publication in MEDLINE using the same approach as in Vaccario et al. (2020) and Verginer and Riccaboni (2020, 2021). MEDLINE provides open access to more than 26 million records of scientific publications, with most of the corpus covering research in the life sciences. Specifically, we use Author-ity (Torvik and Smalheiser 2009), a dataset which allows us to identify an author across publications and Mapaffil (Torvik 2015), a dataset with disambiguated affiliation records. By combining these two data sources, we obtain individual-level mobility trajectories as witnessed by their scientific output in MEDLINE. To identify a move, we look at a scientist's publication history. The scientific publications by a single author are shown as a sequence of circles from top to bottom. Each publication has a date (in rows) and location (in columns) associated with it. We 
Fig. 4 Reconstructing the intericty/state mobility. The scientific publications by a single author are illustrated as a sequence of green circles from top to bottom. Each publication has a time (in rows) and location (in columns) associated with it

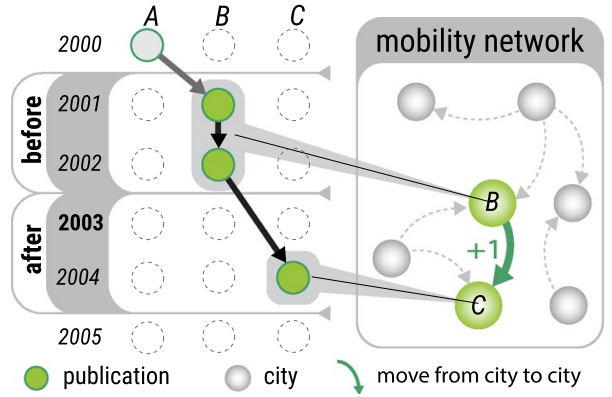

look at 2 years before a given year (e.g. 2003) and two after. In the example in Fig. 4, we identify $B$ as the source and $C$ as the target of the move.

\subsection{Productivity}

We know that productivity of researchers affect their mobility patterns and therefore must be controlled for. As in Verginer and Riccaboni (2021), we control for individual-level productivity by computing for each author, and every year, a citation-based productivity measure. Specifically, we compute it using the impact factor of the journals the author has published in the 2 years before the move and correct for the number of co-authors. For journal impact analysis, we rely on the SCImago (2020) dataset. This online database offers comprehensive journal indicators obtained from the canonical Scopus Database.

For example, let us assume an author publishes two papers with three co-authors each in the 2 years before a move. One paper is published in a journal which got 20 citations per document in the past 2 years and 1 in a journal which got two citations per document in the past 2 years. In this example, the author obtains a productivity value of $5.5=20 / 4+2 / 4$. In the regression analysis, we use the natural log of this number to proxy the productivity of the author since scientific productivity is highly skewed.

\subsection{Identification of hESC researchers}

We identify Stem Cell researchers through the titles and abstracts of papers they have published in MEDLINE. We distinguish four types of researchers. These four classes of researchers have an increased likelihood of being subject to hESC regulation in their work. (1) Other Life Scientists (NoSC), represent all scientists available in MEDLINE for the relevant period but have never mentioned "Stem Cells" in their work and have never worked with anyone discussing "Stem Cell" in their work. This group should be mostly unaffected by Stem Cell legislation. (2) Stem Cell (SC) researchers, are scientists who work on stem Cells in general but not on "embryos" or "human embryos". This group might be impacted directly or indirectly by state legislation. The same reasoning goes for (3) Embryonic Stem Cell (ESC) researchers 


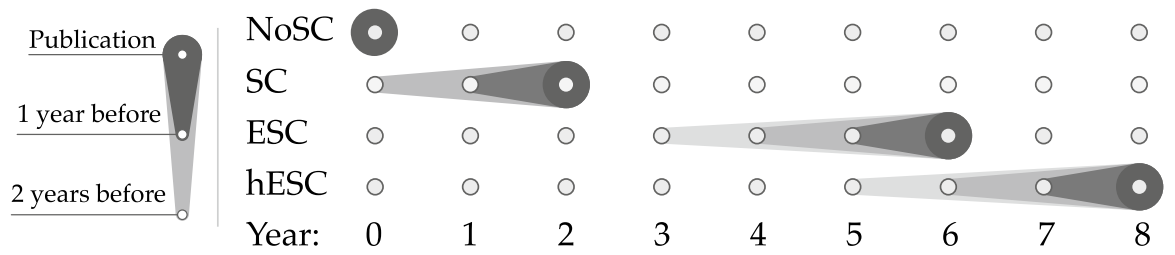

Fig. 5 Identification of SC researchers. The illustration shows an author becoming active in year 0 by publishing a NoSC paper. In the subsequent years, she publishes on SC, ESC and hESC. Since a publication is a delayed signal of activity, her type is determined several years prior. Using an offset of 3 years, she is an SC scientist in 0, ESC in 3 and hESC in year 5

who might experiment on "embryos" but not of the "human" kind. Finally, the most likely researchers to be affected are (4) human Embryonic Stem Cell (hESC) researchers which explicitly mention human embryos in their research. Specifically, to identify researchers working on SC, ESC and hESC, we proceed as follows. We collect all publications in MEDLINE marked as Journal Article and filter out papers which contain the following strings either in the title or the abstract. ${ }^{2}$

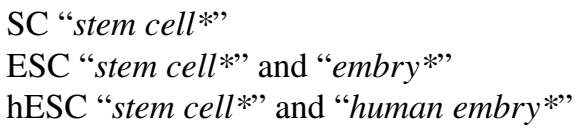

Here "*" represents a wild-card matching any subsequent letter if it is not interrupted by white-space. We restrict our search to Documents of type Journal Article to minimize the chance that we pick up commentary on stem cell and not actual hESC research. An alternative to the simple text-based search is to use the MeSH (Medical Subject Headings), a key-word classification system maintained by the National Library of Medicine. However, the term "Fetal Stem Cells" has only been introduced in 2006 as a refinement of "Stem Cells", and therefore is not available in the period of interest.

We adopt the following convention to take into account, that hESC researchers might not necessarily start their career carrying out hESC research. A scientist who has published a paper on hESC in year $t$ is marked as being an hESC researcher 3 years before $(t-3)$. A conceptual illustration of this definition is available in Fig. 5.

If a scientist has published work falling in multiple categories, she is always placed in the most exposed group. So, for example, a scientist classified as both $\mathrm{hESC}$ and SC would be classified only as hESC.

We adopt this convention for three reasons. First, the publication represents a delayed signal of the actual research, i.e., if a paper appeared in 2005, it stands to reason that the work was carried out a few years prior. Second, we do only observe papers available in MEDLINE, which does not offer universal coverage. Therefore,

\footnotetext{
2 The full text of the articles is only available for a subset of MEDLINE, and only abstract and title are readily available.
} 
Table 1 Distribution of scientists according to affiliation type

\begin{tabular}{lllll}
\hline & hESC & ESC & SC & NoSC \\
\hline Educational & 79.8 & 81.6 & 77.9 & 77.6 \\
Hospital & 5.4 & 5.4 & 9.4 & 7.2 \\
Research organization & 10.3 & 10.9 & 9.6 & 8.9 \\
Unknown & 1.3 & 0.8 & 0.7 & 1.4 \\
Military & 0.2 & 0.2 & 0.1 & 0.4 \\
Government & 0.2 & 0.2 & 0.2 & 0.6 \\
Commercial & 2.7 & 1.8 & 2.0 & 3.8 \\
\hline
\end{tabular}

we could have missed a prior publication and would classify the researcher as hESC later than we should have. Third, it takes time for a young researcher to start publishing on hESC and thus a publication is a delayed signal of the fact that his career in the previous years was in this field.

The type of organization a scientist works for might affect the financial incentives of public funding restrictions. For example, researchers working for a commercial company might be less likely to require funding from the state or the federal government. As argued in the introduction given the infancy of this technology in the years under consideration, most hESC research has been carried out by scientists working for public institutions, if we look at the distribution of affiliation types, as classified by Torvik (2015), and shown in Table 1.

We see that only $1.8-2.7 \%$ of Stem Cell researchers work for commercial entities, which is also below the $3.8 \%$ we find the in the general scientist population. This observation suggests, first that the scientists in the dataset we consider are by and large research scientist working for public institutions and second that stem cell scientists are more likely to work for public institutions than the general scientist population.

\subsection{Supportive states}

We distinguish between Supportive and Not Supportive legislation (i.e., did not outright declare support yet or are restrictive). We do this since explicitly signaling support is more critical for hESC researcher than omitting or outright declare such research not welcome.

To appreciate the evolution over the years of the distribution of these scientists across the various policy regimes (including "restrictive"), we show in Fig. 6 the breakdown of the four types. The types differ primarily in their number, with each group being substantially smaller than the previous. The low number of stem cell researchers becomes an issue if we consider that most scientists do not move in any given period. 

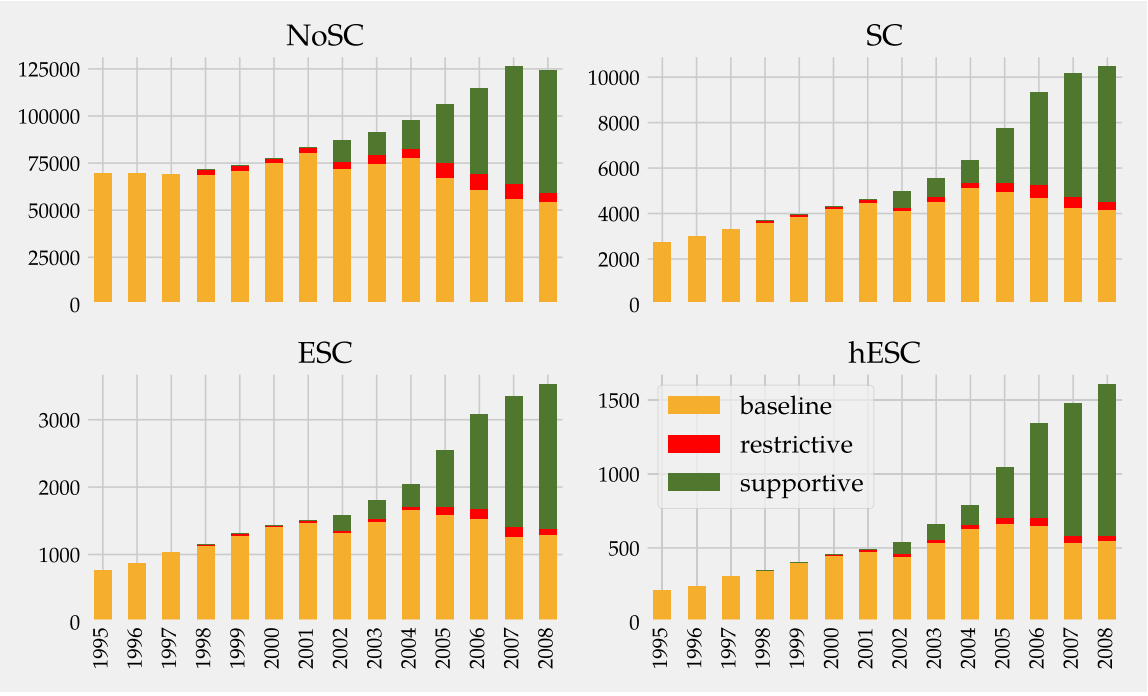

Fig. 6 Distribution over the years of researchers according to the stance of the state they work in. The stance of the state changes over the years

\section{Results}

Before we address the impact of the two primary legislative intervention, i.e., Bush Ban and Proposition 71, we will characterize how the Stem Cell research population is distributed across the US.

In the analysis, we will be using the following variables and controls.

Supportive Equal to 1 if the state in the given year is supportive and 0 otherwise (i.e., not supportive)

StemType Dummy variables identifying the four classes of Stem Cell researchers, the NoSC is the always the base case

Productivity The Productivity of the author as described in detail in Data Section. Age group Age is measured as the difference in years from first publication to the move year. The age-groups are split such that the cohorts are of comparable size

State The state the author was in before the year the move took place

Year The year in which the move took place.

We include productivity to control for the fact that moving and the destination of a move might be correlated with this factor, as the analysis by Verginer and Riccaboni (2021) on the international mobility of scientists suggests. Moreover, the stage in the career of a scientist affects the propensity to move; therefore, we also control for age. We also include both State and Year dummies to alleviate concerns that state and year-specific effects might bias our results. 


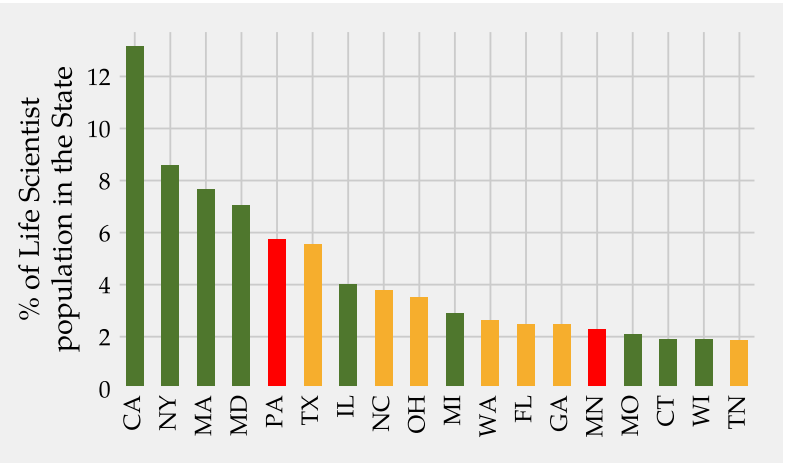

Fig. 7 Percentage of the Life Scientists Population working in 2008 in the given state. The shown states cumulatively account for $80 \%$ of this population

Descriptive statistics and correlation tables are available in the appendix (see Tables 6 and 7).

We look first at the prevalence of researchers across fields to see if there is a bias there, i.e. the distribution of scientists across supportive and non-supportive states.

Not all states are of comparable size in 2008, as suggested by Fig. 7. Supportive states, as declared in 2008, host $50 \%$ of the total population of active life scientists. However, this has not been the case in previous years, where few states enacted outright legislation in support as illustrated by Fig. 6. To see how researchers are distributed across supportive and non-supportive states, we aggregate the state they were located in from 2002 to 2008 . We restrict the interval to this sub-period since before 2002 the number of scientists working in declared supportive states is negligible.

By comparing the relative prevalence in the geographic distribution of hESC researchers across supportive and not supportive states against the NoSC population, we can identify an imbalance. This analysis helps us to validate two things, (1) the validity of the classification itself and (2) geographic imbalance. If the classification of supportive states were not informative, there should not be a discernible difference between the two groups. Specifically, a deviation from the distribution of the NoSC population in favor of supportive states would falsify the assumption that the two populations are distributed proportionally. We do find, however, evidence in Table 2 to support the idea that stem cell researchers prevalently work in declared supportive states. All three levels of exposure (i.e., SC, ESC and hESC) are between 15 and $33 \%$ more likely to be affiliated with institutions located in supportive states than NoSC counterparts.

To make sure that what we observe here is also accurate accounting for state and year effects, we estimate a panel fixed effects model covering the period 1995-2008. We include a more extended period than before since by using a Fixed Effect model we can exploit the change from not supportive to supportive for a state:

$$
\log (\text { ESC Pop. })_{s t}=\beta_{0}+\beta_{1} \log (\text { Total Pop. })_{s t}+\beta_{2} \text { Supportive }_{s t}+\alpha_{s}+u_{s t} \text {. }
$$


Table 2 Distribution for the four classes of researchers in the period 2000-2008 by the state's supportive stance as they are distributed

\begin{tabular}{|c|c|c|c|c|}
\hline & \multicolumn{2}{|c|}{ Supportive } & \multicolumn{2}{|c|}{ Not supportive } \\
\hline & Prop (\%) & $\Delta \%$ & Prop (\%) & $\Delta \%$ \\
\hline NoSC & 32.4 & & 67.6 & \\
\hline $\mathrm{SC}$ & 37.2 & +15.0 & 62.8 & -7.2 \\
\hline $\mathrm{ESC}$ & 39.9 & +23.2 & 60.1 & -11.1 \\
\hline hESC & 43.1 & +33.1 & 56.9 & -15.8 \\
\hline
\end{tabular}

Prop indicates what proportion of researchers are found in that class. For example authors without any connection to Stem Cells have a concentration of $32.4 \%$ in supportive states. The $\Delta \%$ indicates by how much the Stem scientist populations deviate from the NoSC population, i.e., hESC/NoSC-1

Table 3 Fixed Effect regression on the log of the population stocks

\begin{tabular}{llll}
\hline & $(1)$ & $(2)$ & $(3)$ \\
& $\log ($ Pop. SC $)$ & $\log ($ Pop. ESC $)$ & $\log ($ Pop. hESC) \\
\hline $\log$ (Pop Tot.) & $1.157^{* * *}(32.10)$ & $0.913^{* * *}(22.03)$ & $0.753^{* * *}(15.91)$ \\
Supportive & $0.288^{* * *}(5.04)$ & $0.357^{* * *}(5.00)$ & $0.585^{* * *}(6.14)$ \\
Constant & $-4.048^{* * *}(-16.13)$ & $-3.467^{* * *}(-12.15)$ & $-3.238^{* * *}(-10.06)$ \\
Observations & 593 & 593 & 593 \\
$R_{\text {within }}^{2}$ & 0.656 & 0.449 & 0.333 \\
$R_{\text {between }}^{2}$ & 0.865 & 0.786 & 0.686 \\
$R_{\text {overall }}^{2}$ & 0.861 & 0.781 & 0.658 \\
\hline
\end{tabular}

$t$ statistics in parentheses

${ }^{*} p<0.10,{ }^{* *} p<0.05,{ }^{* * *} p<0.01$

We estimate the log of the hESC population as a function of the stance of the state in that year and the size of the entire Life Scientists population in that state. Where $\log$ (ESC Pop. $)_{s t}$ is the log of the scientists identified as ESC active in state $s$ in year $t$. Similarly $\log$ (Total Pop. $)_{s t}$ refers to the total population of active scientists in the

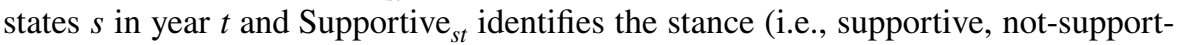
ive) of state $s$ in year $t$. Note that the base-case for the state policy stance in the regression is "not supportive". The results of the panel regression in Table 3 suggest, in accordance with Table 2, that there is a preference for hESC scientists to work in supportive states. The scientist population of the state explains a large part of the variance. In fact, Fig. 7 shows that the largest states are indeed supportive. ${ }^{3}$

In conclusion, we find that scientists with high exposure to stem cell legislation tend to work in supportive states.

\footnotetext{
3 We have tested for robustness also random effect specifications in addition to carrying out regressions on the raw population counts. The results confirm that more supportive states host a larger proportion of stem cell scientists and especially hESC scientists. The regression is available upon request.
} 
Table 4 Logit regression with dependent variable the destination type

\begin{tabular}{llll}
\hline & $(1)$ & $(2)$ & $(3)$ \\
& Supportive & Not supportive & Abroad \\
\hline SC & $0.138^{* * *}$ & $-0.110^{* * *}$ & $0.0642^{* *}$ \\
ESC & 0.0700 & $-0.188^{* * *}$ & $0.187^{* * *}$ \\
hESC & 0.0988 & -0.0230 & -0.0177 \\
Supportive & $1.047^{* * *}$ & $-0.819^{* * *}$ & -0.0163 \\
Supportive $\times$ SC & $-0.211^{* * *}$ & 0.0642 & 0.0406 \\
Supportive $\times$ ESC & -0.190 & 0.0647 & 0.0583 \\
Supportive $\times$ hESC & 0.0339 & -0.111 & -0.0429 \\
Productivity & $0.0330^{* * *}$ & -0.00950 & -0.0114 \\
Constant & $-5.980^{* * *}$ & $1.769^{* * *}$ & $-1.606^{* * *}$ \\
Age effects & Yes & Yes & Yes \\
Year effects & Yes & Yes & Yes \\
State effects & Yes & Yes & Yes \\
Observations & 287,913 & 287,918 & 287,918 \\
Log likelihood & $-109,877.3$ & $-176,447.3$ & $-158,996.0$ \\
Pseudo $R^{2}$ & 0.232 & 0.107 & 0.00763 \\
\hline
\end{tabular}

The errors are clustered at the source state year level (572 clusters) ${ }^{*} p<0.10,{ }^{* *} p<0.05,{ }^{* * *} p<0.01$

So far, we have noted that two forces are affecting the relocation choice of hESC researchers, which could confound our estimates to move from not-supportive to supportive. We have found that in general hESC researchers are already predominantly residing and working in supportive states and have a lower propensity to move than their counterparts in not supportive states. Nevertheless, we can estimate for mobile researchers who do indeed change move to a different city in a given year where the target city is most likely to be. More precisely, we estimate the Logit model shown in Table 4. Where TargetType ${ }_{i}$ and SourceType ${ }_{i}$ are the stance of the state inventor $i$ moved from and to respectively. The variable StemType identi- $_{i}$ fied the type of researcher $i$. Additionally, we control for the age group the author falls in (cohorts of 2 years, e.g. researchers from 1 to 2 years are grouped, as are 10-11 years old researchers).

We do find that researchers, in general, are more likely to move to supportive states. Moreover, ESC researchers are less likely to move to "Not supportive states" then the general NOSC population. However, we do not find a discernible difference for hESC researcher to move preferentially to supportive states above and beyond what we would expect from the general mobility patterns. These findings suggest that there are mixed signals with regards to $\mathrm{H} 1$. We do have evidence that stem cell 


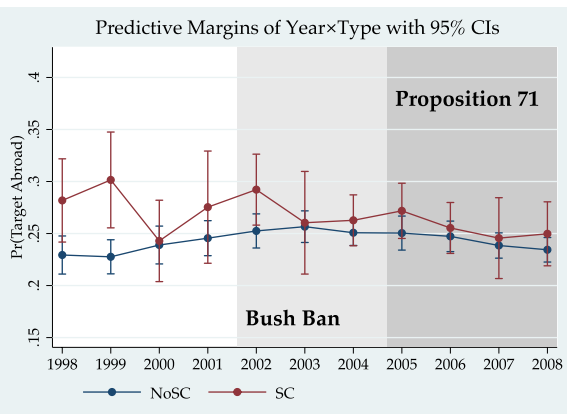

(a)

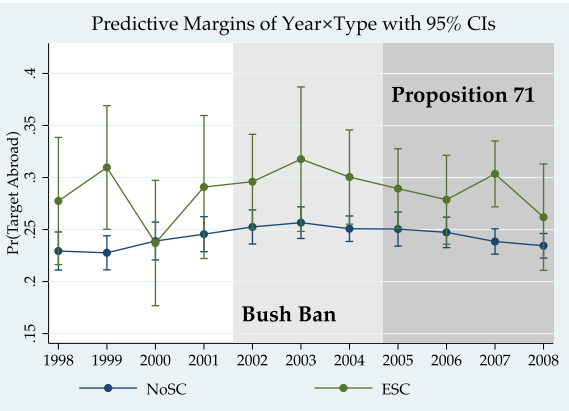

(b)

Fig. 8 Marginal Probability to move abroad, for researchers which move in a given year (i.e., $\operatorname{Pr}($ Move Abroad|Leaving city, $X)$ ): a SC vs NoSC, b ESC vs NoSC

researchers are already predominantly working in supportive states, and thus this could negatively affect our estimate. The most confident claim we can make with regards to $\mathrm{H} 1$ is that there might be a tendency for hESC researchers to move to supportive states, but the effect is masked by the fact that most hESC researchers are already in supportive states and that these do not move as much, once there.

\subsection{Mobility abroad following the Bush Ban}

Following the general characterization of the geographic distribution of researchers, we address now the remaining hypotheses of this work.

First, we investigate $\mathrm{H} 2$, the claim that hESC researchers left the US following the announcement of the Bush Ban in the August of 2001. We have noted that there are no clear preferences for hESC scientists to move abroad (there is for ESC), but there could have been a peak over the years which we have averaged out. To test the hypothesis that there was an uptick in moves abroad, we estimate a logit model with a dummy for each year and type of researchers. We consider only researchers who did indeed move to another city.

$$
\begin{aligned}
\text { Move Abroad }_{i t}= & \beta_{0}+\beta_{1} \text { Supportive }_{i t} s+\beta_{2} \text { Year }_{i t} \times \text { StemType }_{i t} \\
& +\beta_{3} \text { Productivity } \\
& + \text { Age Group } \\
\text { Ag } & + \text { Year }+ \text { State }+u_{i t}
\end{aligned}
$$

The detailed results of this regression are available in the Appendix in Table 8. We note that controlling for state effects, we do not find a significant difference between researchers in supportive and restrictive states in their tendency to move abroad. However, we do observe some differences in yearly marginal probabilities to move abroad for the four researcher types.

In Fig. 8a we show the probability to move abroad for unaffected group NoSC and the largely unaffected SC group. Note that except for 1999-well before both the Bush Ban and Proposition 71- the two groups have the same propensity to move abroad, suggesting that SC has not been materially affected by either the Bush 
Fig. 9 Marginal probability to move abroad, for researchers which move in that year

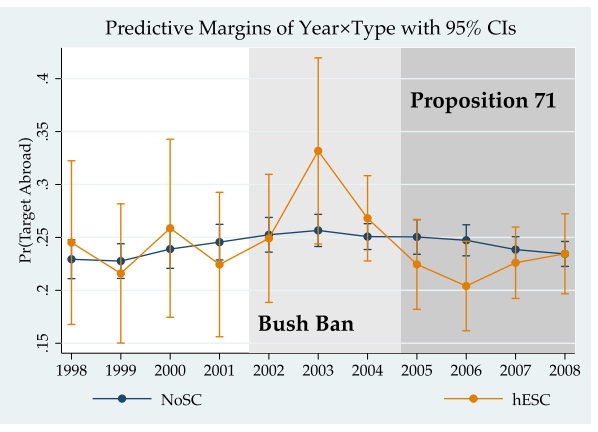

Ban or Proposition 71. This result suggests that SC are mostly unaffected. Similarly, the more at-risk group ESC, shown in Fig. 8b, is more likely to leave the country then NoSC. This trend can be observed for most of the period and is in line with the results in Table 4. Importantly the trend does not seem to be affected by the two legislative measures. These results point again to the fact that stem cell research as a whole is not materially affected.

We do find that hESC, researchers working with human embryos, seem to respond to the two treatments, as shown in Fig. 9. The trend from 1998 to 2002 is statistically not distinguishable from NoSC, suggesting that mobility abroad before the Bush Ban was in line with general Life Scientists. However, in 2003, there is a sudden uptick in mobility abroad, which is quickly reversed and tends below NoSC after 2005. The difference is not significant at the 95\% confidence level, as the overlapping error bars suggest. Still, the sudden shift in trend could indicate the influence of the Bush Ban or Proposition 71. A similar conclusion is supported by comparing ESC and hESC, which is a comparable group in numbers and research focus.

With regards to $\mathrm{H} 2$, we do not find conclusive evidence that hESC mobility has materially increased following the funding ban. We do, however, find that unlike the other at-risk groups (SC and ESC) the mobility abroad seems to be affected by the ban. The sudden drop off after 2005 could simply be a reversal to the mean, or it could have been influenced by Proposition 71 .

\subsection{California and Proposition 71}

We address in this section the remaining two hypotheses related to the passage of Proposition 71. Specifically, we estimate the probability to move to California, conditional on observing a move to another city. In other words, the variable "Moved To California", the primary variable of interest in this model, is equal to 1 if a given scientist moves to California in the given year, and 0 if the given scientist moves to a different country or city which is not in California. We also do not include scientists who are already based in California and move to a different city. Precisely, we estimate the following repeated cross-section model where each observation identifies a mobility decision in 1 year. 


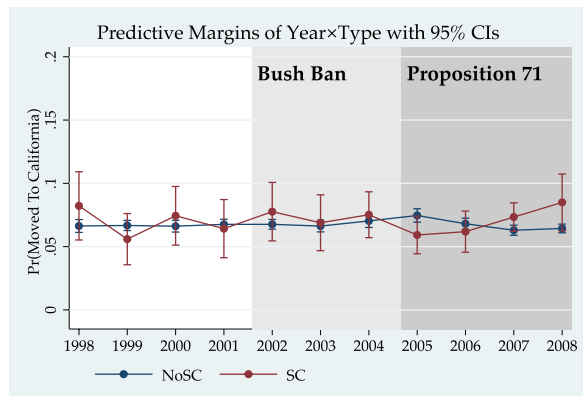

(a)

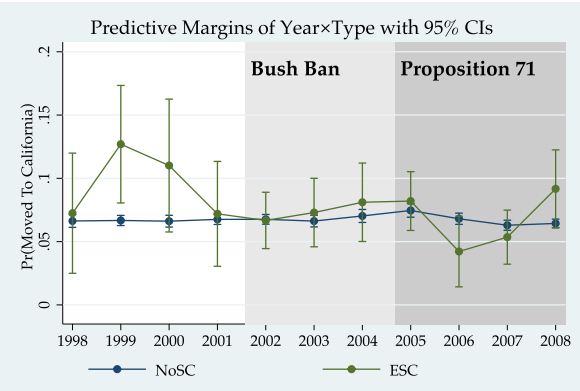

(b)

Fig. 10 Marginal probability to move to California for a NoSC vs SC and b ESC vs NoSC

$$
\begin{gathered}
\text { Move To California }_{i}=\beta_{0}+\beta_{1} \text { Supportive }_{i} \\
+\beta_{2} \text { Year }_{i} \times \text { StemType }_{i} \\
+\beta_{3} \text { Productivity }_{i} \\
+\beta_{4} \text { Age Group }_{i}+\text { Year }_{i} \\
+ \text { State }_{i}+u_{i}
\end{gathered}
$$

In Table 1, the regression results are outlined. We compare the marginal probability to move to California over time for the various researcher types to understand if there has been a sudden influx of scientists following either the Bush Ban or Proposition 71.

As in the previous section, we look at the marginal predicted probabilities to move to California for the at-risk groups in sequence. We can verify again in Fig. 10 that the SC group is virtually identical to the NoSC in its propensity to move to California and neither the Bush Ban nor Proposition 71 seem to have had an effect.

The ESC group, the second most at-risk group, similarly does not deviate in its propensity to move to California from the NoSC group. However, there seems to be a drop in mobility toward California in 2006, which quickly reversed. What is clear is that the announcement of the Bush Ban did not materially affect ESC's propensity to move to California and Proposition 71 did not increase this propensity.

However, the impact of the two policies is different for the group most likely to be affected by both legislation, i.e., hESC. We can observe that the propensity of hESC researchers to move to California is in line with what we expect it to be in the three policy regimes. In the pre Bush Ban (1998-2001) it is in line with general mobility trends. In the years after but before the vote on Proposition 71 (2002-2004), it dropped due to mobility abroad. And finally it reversal after the adoption of Proposition 71 (2005-2008). The magnitude of the policy impact is not negligible, jumping from 5\% just before Proposition 71 in 2003, to $12 \%$ in 
Fig. 11 Marginal probability to move to California for both NoSC and hESC

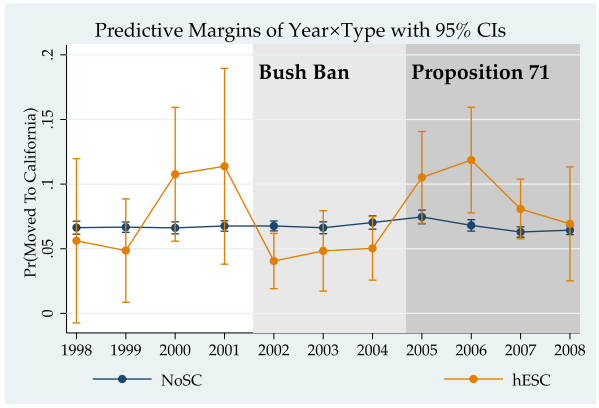

2006. In the years that follow this trend reverses to the NoSC mean of $7 \%$. By considering the 95\% confidence bounds, the jump from 2002 to 2006 is significant, assuming common trends with either NoSC or SC.

In addition to the divergence of the propensities to move to California, we have also seen that hESC scientists are concentrated in supportive states and tend to stay in supportive states. These two factors arguably reduce the observed effect size, given that most scientists are already where they want to be, either because they moved there and do not want to relocate or because they started their career there.

By comparing Fig. 9, the probability of hESC researchers to move abroad with Fig. 11, the likelihood of hESC researchers to move to California, we note that the responses to the two policies are mirrored. Where we observe an increase in mobility abroad, from 2002 to 2004, we see a drop in moves to California, and analogously after the vote on Proposition 71, we observe a reduction in mobility abroad and an uptick in mobility towards California. This "mirror effect" suggests the possible existence of a substitution effect, whereby mobility to California is substituted with mobility abroad post Ban announcement and post-Proposition 71 a shift from abroad to California.

To further strengthen our claim that Proposition 71 has had the overall effect of reducing mobility abroad and increasing retention of hESC scientists in the US in general and in California, in particular, we look at the marginal predicted probability to leave California over the same period. The probabilities for the least affected groups are shown in Fig. 12, where we note that SC has not been affected. The propensity to leave California if anything has increased above and beyond the baseline NoSC group.

However, as expected and in line with the results on the propensity to move abroad and to California, we find that the tendency for hESC researchers to leave California mirrors the trend to leave the country as shown in Fig. 9. This result suggests that the adoption of Proposition 71, has not only increased mobility towards California but has dissuaded scientists from leaving the state.

We carry out the same analysis by considering only SC and hESC researchers (see Table 5).

By doing so, we can see the effect by comparing only two similar groups of scientists, namely hESC (the main focus) and SC. The SC is a control group which 


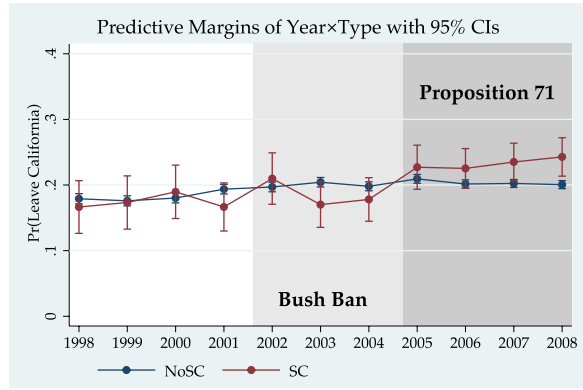

(a)

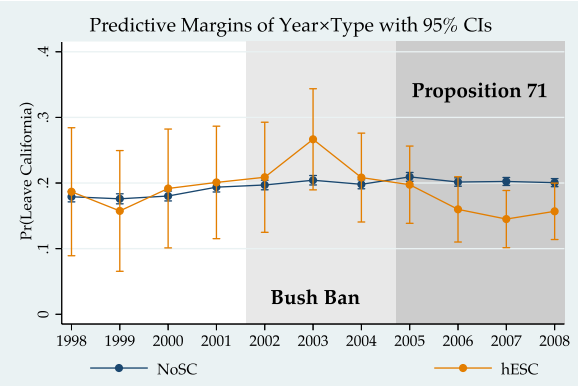

(b)

Fig. 12 Marginal Predicted probability to leave California comparing: a NoSC vs SC and b hESC vs NoSC

Table 5 Comparing the propensity of hESC to move abroad and to CA by using SC (not dealing with human embryos) as a base case

\begin{tabular}{lll}
\hline & Moved abroad & Moved to CA \\
\hline hESC $\times 1999$ & $-0.459^{* *}$ & -0.133 \\
hESC $\times 2000$ & 0.0469 & 0.424 \\
hESC $\times 2001$ & -0.307 & 0.704 \\
hESC $\times 2002$ & -0.321 & $-0.678^{*}$ \\
hESC $\times 2003$ & $0.393^{* *}$ & -0.395 \\
hESC $\times 2004$ & -0.0369 & -0.369 \\
hESC $\times 2005$ & -0.179 & $0.673^{* *}$ \\
hESC $\times 2006$ & -0.231 & $0.773^{* * *}$ \\
hESC $\times 2007$ & 0.00623 & 0.148 \\
hESC $\times 2008$ & 0.0255 & -0.153 \\
Supportive & 0.0121 & 0.00565 \\
Productivity & $-0.0689^{* * *}$ & 0.0345 \\
Constant & $-0.991^{* * *}$ & $-2.245^{* * *}$ \\
Year effects & Yes & Yes \\
Age effects & Yes & Yes \\
State effects & Yes & Yes \\
Observations & 10,350 & 10,177 \\
LogLikelihood & -6221.3 & -2594.4 \\
Pseudo $R^{2}$ & 0.0335 & 0.0273 \\
\hline & &
\end{tabular}

Errors clustered at state-year level (415 clusters)

${ }^{*} p<0.10,{ }^{* *} p<0.05,{ }^{* * *} p<0.01$

operates in a very similar environment but has not been impacted by either federal or state level legislation which is concentrated on human embryos. We find that the mobility towards CA for hESC is significantly higher in 2005 and 2006, after 
Proposition 71, and mobility of hESC scientists abroad spikes in 2003, after the Bush Ban.

\section{Discussion and conclusion}

From our analysis, the following stylized facts regarding the mobility patterns of hESC researchers in the period 1998-2008 in the US emerges:

1. hESC scientists are more likely to work in supportive states.

2. hESC scientists working in a supportive state are less likely to move than their counterparts in non-supportive states.

3. However, given the first two results, we do not find a significant preference for hESC researchers to move to supportive states (weak support for $\mathrm{H} 1$ ).

4. Mobility abroad did not significantly increase for the at-risk groups. The hESC group did experience a single uptick in abroad moves, which was quickly reversed; thus, we do not find support for $\mathrm{H} 2$.

5. Following the vote on Proposition 71, the drop in moves towards California is reversed, lending support to $\mathrm{H} 3$.

6. Following Proposition 71, hESC scientists leave California with a lower probability, supporting $\mathrm{H} 4$.

The overall pattern that emerges from the analysis is that the varied approaches to stem cell research have had an impact on the geographic distribution of hESC researchers across the US. Supportive states do employ more hESC scientist than non-supportive states, and more importantly, once working in a supportive state, these scientists do not leave.

Specifically, concerning the two most important pieces of legislation excluding the Obama era, i.e., restrictions on funding put in place by Bush, and the 3 Billion Dollar funding scheme in California, we find that the supportive state-level legislation has counteracted the restrictive federal stance. There is some indication that hESC scientists were headed abroad following the ban in 2001. This trend reversed nearly immediately, and in fact, we do find that hESC researchers are less likely to leave the country or California, than their less exposed counterparts after 2004.

We find that state legislation and funding has had the overall effect of mitigating an anticipated exodus of hESC researchers following the Bush Ban. We argue that this is because viable alternatives to move to within the US emerged. A prime example of which is California with Proposition 71. According to our analysis, this funding scheme has attracted scientists to California and reduced the propensity of Californian scientists to leave the state. The nearly simultaneous 
drop in mobility abroad and increase in moves towards California suggests that this initiative, and several state funding schemes that followed, have had the desired effect of averting an exodus of researchers.

More generally, the supportive state response to restrictive federal legislation, suggests that the US national research system has reacted to restrictive federal legislation through lobbying at the state level. HESC research as a whole has been affected by restrictive state, and federal legislation as the geographic redistribution of hESC researchers suggest. However, the ability of individual states to step in and experiment with new laws has by and large negated the effect of federal restrictions and allowed hESC research in the US to flourish. The observed dynamics of state legislation counteracting federal rules is a prime example of partisan politics playing out at the two levels.

Overall this study points to the fact that hESC research, being a controversial topic in the US has led to spatial segregation, whereby hESC researchers are concentrated in supportive states. More importantly, however, restrictive federal and state laws have been negated by permissive legislation which has most likely thwarted a possible departure of hESC researchers. The two-tier approach to hESC legislation is, therefore, an example of how the US national research system reacted to restrictions. According to some commentators (Salter and Harvey 2008; Gottweis and Prainsack 2006; Klitzman and Sauer 2009; Levine 2008), the bearish stance on hESC by the federal government could have compromised the standing of US hESC research for years to come. However, it looks like the national research system was resilient to this threat as indicated by our analysis and the continued leadership of the US in Stem Cell research.

\section{Appendix}

Tables 6 and 7 list the summary statistics and cross-correlations of the variables used in the analysis respectively. 
Table 6 Summary statistics

\begin{tabular}{|c|c|c|c|c|}
\hline & Mean & $\mathrm{SD}$ & Min & Max \\
\hline \multicolumn{5}{|l|}{$\mathrm{NoSC}$} \\
\hline Moved & 0.24 & 0.43 & 0 & 1 \\
\hline Moved state & 0.19 & 0.39 & 0 & 1 \\
\hline Age & 9.73 & 8.92 & 1 & 81 \\
\hline Papers & 12.64 & 20.10 & 1 & 658 \\
\hline Productivity & 3.13 & 5.01 & 0.00 & 590.34 \\
\hline $\begin{array}{l}\text { Distance } \\
S C\end{array}$ & 723.52 & 2181.07 & 0 & $18,776.57$ \\
\hline Moved & 0.21 & 0.40 & 0 & 1 \\
\hline Moved state & 0.17 & 0.38 & 0 & 1 \\
\hline Age & 13.07 & 9.90 & 1 & 62 \\
\hline Papers & 25.69 & 41.15 & 1 & 1460 \\
\hline Productivity & 5.36 & 8.27 & 0.00 & 176.01 \\
\hline Distance & 669.41 & 2128.92 & 0 & $18,707.05$ \\
\hline \multicolumn{5}{|l|}{$E S C$} \\
\hline Moved & 0.22 & 0.41 & 0 & 1 \\
\hline Moved state & 0.19 & 0.39 & 0 & 1 \\
\hline AGE & 13.35 & 9.93 & 1 & 66 \\
\hline Papers & 27.71 & 38.98 & 1 & 467 \\
\hline Productivity & 6.72 & 9.03 & 0.00 & 138.14 \\
\hline Distance & 754.26 & 2257.33 & 0 & $18,663.88$ \\
\hline \multicolumn{5}{|l|}{$h E S C$} \\
\hline Moved & 0.22 & 0.41 & 0 & 1 \\
\hline Moved state & 0.18 & 0.38 & 0 & 1 \\
\hline Age & 13.43 & 9.93 & 1 & 61 \\
\hline Papers & 30.49 & 46.13 & 1 & 518 \\
\hline Productivity & 7.47 & 11.02 & 0.01 & 235.59 \\
\hline Distance & 666.11 & 2086.49 & 0 & $16,932.99$ \\
\hline Observations & $1,367,767$ & & & \\
\hline
\end{tabular}

Table 7 Cross-correlation table

\begin{tabular}{lllll}
\hline Variables & Moved & Moved state & Age & Productivity \\
\hline Moved & 1.000 & & & \\
Moved_state & 0.872 & 1.000 & & \\
Age & -0.100 & -0.102 & 1.000 & \\
Productivity & -0.081 & -0.072 & 0.252 & 1.000 \\
\hline
\end{tabular}

\section{Move abroad and California}

See Table 8. 
Table 8 Regression result for the estimation of the yearly propensity of stem cell scientists to move abroad and to California

\begin{tabular}{|c|c|c|}
\hline & Moved abroad & Moved to CA \\
\hline $\mathrm{SC} \times 1999$ & $0.360^{* * *}$ & -0.189 \\
\hline $\mathrm{SC} \times 2000$ & 0.00395 & 0.127 \\
\hline $\mathrm{SC} \times 2001$ & 0.130 & -0.0554 \\
\hline $\mathrm{SC} \times 2002$ & $0.171^{* *}$ & 0.149 \\
\hline $\mathrm{SC} \times 2003$ & -0.00537 & 0.0416 \\
\hline $\mathrm{SC} \times 2004$ & 0.0411 & 0.0733 \\
\hline $\mathrm{SC} \times 2005$ & $0.0961^{*}$ & -0.249 \\
\hline $\mathrm{SC} \times 2006$ & 0.0277 & -0.103 \\
\hline $\mathrm{SC} \times 2007$ & 0.0233 & $0.165^{*}$ \\
\hline $\mathrm{SC} \times 2008$ & 0.0647 & $0.301^{* *}$ \\
\hline $\mathrm{ESC} \times 1999$ & $0.393^{* *}$ & $0.715^{* * *}$ \\
\hline $\mathrm{ESC} \times 2000$ & -0.0333 & $0.561^{* *}$ \\
\hline $\mathrm{ESC} \times 2001$ & 0.223 & 0.0677 \\
\hline $\mathrm{ESC} \times 2002$ & 0.198 & -0.0139 \\
\hline $\mathrm{ESC} \times 2003$ & 0.268 & 0.105 \\
\hline $\mathrm{ESC} \times 2004$ & $0.217^{*}$ & 0.155 \\
\hline $\mathrm{ESC} \times 2005$ & 0.180 & 0.104 \\
\hline $\mathrm{ESC} \times 2006$ & 0.139 & -0.508 \\
\hline $\mathrm{ESC} \times 2007$ & $0.316^{* * *}$ & -0.172 \\
\hline $\mathrm{ESC} \times 2008$ & 0.135 & $0.386^{* *}$ \\
\hline hESC $\times 1999$ & -0.117 & -0.338 \\
\hline $\mathrm{hESC} \times 2000$ & 0.0746 & $0.535^{*}$ \\
\hline $\mathrm{hESC} \times 2001$ & -0.155 & 0.575 \\
\hline $\mathrm{hESC} \times 2002$ & -0.0540 & $-0.543^{*}$ \\
\hline $\mathrm{hESC} \times 2003$ & $0.349^{*}$ & -0.335 \\
\hline $\mathrm{hESC} \times 2004$ & 0.0539 & -0.357 \\
\hline hESC $\times 2005$ & -0.173 & $0.380^{*}$ \\
\hline $\mathrm{hESC} \times 2006$ & $-0.255^{* *}$ & $0.614^{* * *}$ \\
\hline $\mathrm{hESC} \times 2007$ & -0.0561 & $0.270^{*}$ \\
\hline $\mathrm{hESC} \times 2008$ & 0.000477 & 0.0788 \\
\hline Supportive & -0.0138 & 0.0127 \\
\hline Productivity & -0.0115 & $0.0812^{* * *}$ \\
\hline Constant & $-1.611^{* * *}$ & $-3.746^{* * *}$ \\
\hline Year effects & Yes & Yes \\
\hline Age effects & Yes & Yes \\
\hline State effects & Yes & Yes \\
\hline Observations & 287,918 & 242,845 \\
\hline LogLikelihood & $-158,981.5$ & $-59,539.5$ \\
\hline Pseudo $R^{2}$ & 0.00772 & 0.00944 \\
\hline
\end{tabular}

Errors clustered at state-year level (576 clusters)

${ }^{*} p<0.10,{ }^{* *} p<0.05,{ }^{* * *} p<0.01$ 
Funding Open Access funding provided by ETH Zurich.

Availability of data and material The raw XML data on all MEDLINE articles is available for download from the NIH at https://www.nlm.nih.gov/databases/download/pubmed_medline.html, ftp://ftp.ncbi.nlm. nih.gov/pubmed/baseline. The disambiguation of authors (Authority) (Torvik and Smalheiser 2009) and affiliations (MapAffil) (Torvik 2015) has been obtained from http://abel.lis.illinois.edu/downloads.html. Access to this resource can be requested for free from the maintainers through the online form on the same page. Note that due to an agreement with the providers of Authority and MapAffil, these datasets may only be shared by requesting access through the previously mentioned online form. Access to the processed dataset can be requested from the corresponding author.

\section{Compliance with ethical standards}

Conflict of interest The authors declare that they have no conflict of interest.

Code availability Replication Code and Data can be requested from the corresponding author, upon reasonable request.

Open Access This article is licensed under a Creative Commons Attribution 4.0 International License, which permits use, sharing, adaptation, distribution and reproduction in any medium or format, as long as you give appropriate credit to the original author(s) and the source, provide a link to the Creative Commons licence, and indicate if changes were made. The images or other third party material in this article are included in the article's Creative Commons licence, unless indicated otherwise in a credit line to the material. If material is not included in the article's Creative Commons licence and your intended use is not permitted by statutory regulation or exceeds the permitted use, you will need to obtain permission directly from the copyright holder. To view a copy of this licence, visit http://creativecommons.org/licen ses/by/4.0/.

\section{References}

Acosta, N. D., \& Golub, S. H. (2016). The new federalism: State policies regarding embryonic stem cell research. The Journal of Law, Medicine \& Ethics, 44(3), 419-436. https://doi.org/10.1177/10731 10516667939. arXiv:15334406

Adelson, J. W., \& Weinberg, J. K. (2010). The California stem cell initiative: Persuasion, politics, and public science. American Journal of Public Health, 100(3), 446-451. https://doi.org/10.2105/ AJPH.2009.168120

Alberta, H. B., Cheng, A., Jackson, E. L., Pjecha, M., \& Levine, A. D. (2015). Assessing state stem cell programs in the United States: How has state funding affected publication trends? Cell Stem Cell, 16(2), 115-118. https://doi.org/10.1016/j.stem.2015.01.007

Baker, L., Deal, B., \& Principal, M. (2004). Economic impact analysis Proposition 71 California stem cell research and cures initiative. Technical report, Analysis Group

Caulfield, T., Zarzeczny, A., McCormick, J., Bubela, T., Critchley, C., Einsiedel, E., et al. (2009). The stem cell research environment: A patchwork of patchworks. Stem Cell Reviews and Reports, 5(2), 82-88. https://doi.org/10.1007/s12015-009-9071-3

Cheshire, P. C., \& Magrini, S. (2006). Population growth in European cities: Weather matters-but only nationally. Regional studies, 40(1), 23-37

Chessa, A., Morescalchi, A., Pammolli, F., Penner, O., Petersen, A. M., \& Riccaboni, M. (2013). Is Europe evolving toward an integrated research area? Science, 339(6120), 650-651

Department of Health and Human Services. (2015). Stem cell basics. https://stemcells.nih.gov/info/basic s.htm. Accessed 25 Oct 2020

Faggian, A., Olfert, M. R., \& Partridge, M. D. (2012). Inferring regional well-being from individual revealed preferences: The 'voting with your feet'approach. Cambridge Journal of Regions, Economy and Society, 5(1), 163-180 
Florida, R. (2002). The economic geography of talent. Annals of the Association of American geographers, 92(4), 743-755

Glaeser, E. L., Kolko, J., \& Saiz, A. (2001). Consumer city. Journal of Economic Geography, 1(1), 27-50

Gottweis, H., \& Prainsack, B. (2006). Emotion in political discourse: Contrasting approaches to stem cell governance in the USA, UK, Israel and Germany. Regenerative Medicine, 1(6), 823-829. https://doi. org/10.2217/17460751.1.6.823

Holden, C. (2004). NIH report fuels push to alter us stem cell policy. Science, 303(5664), 1593

Kearl, M. (2010). Dickey-Wicker amendment, 1996. Technical report, Arizona Board of Regents. https:// embryo.asu.edu/pages/dickey-wicker-amendment-1996

Klitzman, R., \& Sauer, M. V. (2009). Payment of egg donors in stem cell research in the USA. Reproductive BioMedicine Online, 18(5), 603-608. https://doi.org/10.1016/S1472-6483(10)60002-8

Levine, A. D. (2008). Identifying under- and overperforming countries in research related to human embryonic stem cells. Cell Stem Cell, 2(6), 521-524. https://doi.org/10.1016/j.stem.2008.05.008

Levine, A. D. (2012). State stem cell policy and the geographic preferences of scientists in a contentious emerging field. Science and Public Policy, 39(4), 530-541. https://doi.org/10.1093/scipol/scs038

Levine, A. D., Lacy, T. A., \& Hearn, J. C. (2013). The origins of human embryonic stem cell research policies in the US states. Science and Public Policy, 40(4), 544-558. https://doi.org/10.1093/scipol/sct005

McMillan, G. S., Narin, F., \& Deeds, D. L. (2000). An analysis of the critical role of public science in innovation: The case of biotechnology. Research Policy, 29(1), 1-8. https://doi.org/10.1016/S0048 $-7333(99) 00030-\mathrm{X}$

Miguélez, E., \& Moreno, R. (2014). What attracts knowledge workers? The role of space and social networks. Journal of Regional Science, 54(1), 33-60. https://doi.org/10.1111/jors.12069

Morescalchi, A., Pammolli, F., Penner, O., Petersen, A. M., \& Riccaboni, M. (2015). The evolution of networks of innovators within and across borders: Evidence from patent data. Research Policy, 44(3), 651-668

National Conference of State Legislatures. (2016). Embryonic and fetal research laws. Technical report. National Conference of State Legislatures. Accessed 16 Sept 2018

Owen-Smith, J., \& McCormick, J. (2006). An international gap in human ES cell research. Nature Biotechnology, 24(4), 391-392. https://doi.org/10.1038/nbt0406-391

Partridge, M. D. (2010). The duelling models: NEG vs amenity migration in explaining us engines of growth. Papers in Regional Science, 89(3), 513-536

Rappaport, J. (2007). Moving to nice weather. Regional Science and Urban Economics, 37(3), 375-398

Russo, E. (2005). Follow the money-The politics of embryonic stem cell research. PLoS Biology, 3(7), 1167-1171. https://doi.org/10.1371/journal.pbio.0030234

Salter, B., \& Harvey, O. (2008). Stem cell innovation in the USA: The benefits of the minimal state. Regenerative Medicine, 3(4), 597-610. https://doi.org/10.2217/17460751.3.4.597

SCImago. (2020). SCImago Journal \& Country Rank [Portal]. http://www.ncs1.org/research/health/ embryonic-and-fetal-research-laws.aspx. Accessed 16 Sept 2020

Scott, C. T., McCormick, J. B., DeRouen, M. C., \& Owen-Smith, J. (2011). Democracy derived? New trajectories in pluripotent stem cell research. Cell, 145(6), 820-826. https://doi.org/10.1016/j. cell.2011.05.032

StemGen (2017). International Database on the Legal and Socio-Ethical Issues in Stem Cell Research. Technical report. McGill University. Accessed 09 Oct 2018 through https://web.archive.org

Takahashi, K., \& Yamanaka, S. (2006). Induction of pluripotent stem cells from mouse embryonic and adult fibroblast cultures by defined factors. Cell, 126(4), 663-676. https://doi.org/10.1016/j. cell.2006.07.024. arXiv:NIHMS150003

Thomson, J. A. (1998). Embryonic stem cell lines derived from human blastocysts. Science. https://doi. org/10.1126/science.282.5391.1145

Torvik, V. I. (2015). MapAffil: A bibliographic tool for mapping author affiliation strings to cities and their geocodes worldwide. D-Lib Magazine, vol. 21, pp. 11-12, NIH Public Access. https://doi. org/10.1045/november2015-torvik

Torvik, V. I., \& Smalheiser, N. R. (2009). Author name disambiguation in MEDLINE. ACM Transactions on Knowledge Discovery from Data, 3(3), 1-29. https://doi.org/10.1145/1552303.1552304

Vaccario, G., Verginer, L., \& Schweitzer, F. (2020). The mobility network of scientists: Analyzing temporal correlations in scientific careers. Applied Network Science, 5(1), 36. https://doi.org/10.1007/ s41109-020-00279-x. arXiv:1905.06142

Vakili, K., \& Blomfield, M. (2016). The research money can't buy: The impact of funding on scientists' research behavior. Available at SSRN 2924532. https://doi.org/10.2139/ssrn.2924532 
Verginer, L., \& Riccaboni, M. (2020). Cities and countries in the global scientist mobility network. Applied Network Science, 5(1), 38. https://doi.org/10.1007/s41109-020-00276-0

Verginer, L., \& Riccaboni, M. (2021). Talent goes to global cities: The world network of scientists' mobility. Research policy, 50(1): 104127. https://doi.org/10.1016/j.respol.2020.104127

Vogel, G. (1999). Capturing the promise of youth. Science, 286(5448), 2238-2239

Wilmut, I., Schnieke, A. E., McWhir, J., Kind, A. J., \& Campbell, K. H. S. (1997). Viable offspring derived from fetal and adult mammalian cells. Nature. https://doi.org/10.1038/385810a0

Publisher's Note Springer Nature remains neutral with regard to jurisdictional claims in published maps and institutional affiliations. 